\title{
As birras na criança
}

Rosa Gouveia*

\section{RESUMO}

Faz-se uma revisão das causas, manifestações e prevalência das birras na criança. São referidas perturbações do neurodesenvolvimento e síndromes genéticos cujo quadro clínico inclui birras, os sinais de alarme que devem levar o médico a considerar uma etiologia secundária e, também, as indicações para terapêutica farmacológica. Sugerem-se várias estratégias a aconselhar aos pais para lidar com as birras dos seus filhos.

Palavras-chave: Birras; Criança.

\section{INTRODUÇÃO}

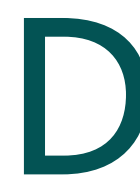

ada a sua elevada prevalência é de esperar que os pais se queixem das birras dos seus filhos e procurem aconselhar-se junto do médico acerca da melhor forma de lidar com o problema. ${ }^{1}$

O clínico deve ser capaz de informar e aconselhar os pais nesta matéria e de destrinçar a birra dita normal da birra como sinal de patologia do neurodesenvolvimento.

\section{EPIDEMIOLOGIA}

As birras surgem igualmente em ambos os sexos, com maior ou menor intensidade, sobretudo em crianças com idades compreendidas entre os 18 e os 48 meses, com um pico entre os 2 e os 3 anos. ${ }^{1,2}$ Coincidem com a altura em que a criança está a adquirir autonomia e a tentar dominar o meio ambiente, razão pela qual alguns autores consideram os 2 anos como $a$ primeira adolescência. ${ }^{3}$ Assim:

- entre os 2 e os 3 anos, $20 \%$ das crianças têm birras pelo menos 1 vez por dia e 50-80\% têm birras pelo menos 1 vez por semana;

- as crianças que têm birras frequentes aos 2 anos continuam, em $60 \%$ dos casos, a ter birras aos 3 anos, e as birras persistem aos 4 anos em $60 \%$ destas;

- o temperamento explosivo mantém-se ao longo da infância em 5\% das crianças;

- as birras excessivas acompanham-se geralmente de outras perturbações do neurodesenvolvimento e comportamento. ${ }^{1}$

*Assistente Hospitalar Graduada de Pediatria

Vice-Presidente da Sociedade de Pediatria do Neurodesenvolvimento da Sociedade Portuguesa de Pediatria
O resultado de um inquérito sobre a prevalência das birras efectuado nos Estados Unidos junto de 1.200 pais revelou uma prevalência de $87 \%$ entre os 18 e os 24 meses, de $91 \%$ entre os 30 e os 36 meses e de $59 \%$ entre os 42 e os 48 meses. $^{2}$

\section{AS BIRRAS NO DESENVOLVIMENTO NORMAL DA CRIANÇA}

As birras são consideradas como uma fase do desenvolvimento normal da criança, caracterizando-se por acessos de cólera em resposta à frustração. ${ }^{1,2,4-9,11,12}$

\section{MANIFESTAÇÕES}

As manifestações da birra são várias: choro, gritos, pontapés, rigidez, extensão dos membros e do tronco. Além disso, a criança pode bater nos outros, bater com a cabeça no chão ou nas paredes, morder-se, atirar-se para o chão, espernear, fugir, atirar com objectos, suster a respiração ou desencadear o vómito.

\section{CAUSAS}

Nestas idades a criança recorre à birra porque não possui, ainda, mecanismos para lidar com a frustração, a sua linguagem verbal é insuficiente, não tem capacidade para perceber o futuro e adiar as suas vontades e tem poucas competências para resolver problemas. Pode, assim, recorrer à birra para chamar sobre si a atenção do adulto ou, sobretudo a partir dos 3 anos quando já domina melhor a linguagem falada, como forma de obter o que quer e de manipular o adulto.,10

\section{FACTORES DESENCADEANTES}

São conhecidos os factores desencadeantes que favore- 
cem o aparecimento da birra: o cansaço, o sono, a fome e certas situações como a refeição, a hora de deitar, as idas ao supermercado ou a falta de atenção. ${ }^{1,2,4-9,11,12}$

\section{SINAIS DE ALARME}

Embora as birras sejam consideradas uma característica normal do desenvolvimento, há sinais preocupantes que devem levar os pais a procurar ajuda e que devem alertar o médico:

- quando as birras aumentam de frequência, duração e intensidade, sendo impossível controlá-las;

- quando a criança se magoa ou magoa os outros;

- quando a criança destrói brinquedos ou outros objectos;

- quando as birras ocorrem na escola;

- quando os pais reagem com agressividade às birras dos seus filhos., ${ }^{3,412}$

\section{AS BIRRAS NA PATOLOGIA DO NEURODESENVOLVIMENTO}

As birras excessivas ou as birras que se prolongam para além da idade habitual podem acompanhar certas perturbações do neurodesenvolvimento, como o défice cognitivo, as perturbações da linguagem, as perturbações do espectro do autismo, a perturbação de défice de atenção e hiperactividade, as perturbações da visão, as perturbações da audição ou as dificuldades escolares. ${ }^{13-19}$ Também fazem parte do quadro clínico de alguns síndromes de causa genética, como o Síndrome de Prader-Willi ou o Síndrome do X Frágil. ${ }^{20,22}$

Pela sua violência, algumas destas birras podem levar a criança a magoar-se ou a magoar os outros, havendo muitas vezes necessidade de recorrer a terapêutica farmacológica, obtendo-se geralmente bons resultados com a risperidona, do grupo dos neurolépticos atípicos, na dosagem de $0,5 \mathrm{mg}$ uma ou duas vezes por dia.

\section{Défice cognitivo}

No défice cognitivo, com uma prevalência de cerca de $3 \%$, o mau desenvolvimento da linguagem e a fraca capacidade para resolver problemas fazem com que a criança recorra à birra para manifestar a sua frustração. A sua dificuldade em perceber o futuro e a sua incapacidade para adiar vontades são igualmente responsáveis pelo recurso à birra, muito para além da idade em que esta é considerada normal. Estas birras podem ser difíceis de controlar, pelo facto de a criança ter dificuldade em entender a argumentação do adulto. ${ }^{13}$

\section{Perturbações da linguagem}

As perturbações da linguagem também são responsáveis por birras excessivas pelo facto de a criança não ser capaz de recorrer à linguagem para manifestar a sua frustração. ${ }^{14}$

\section{Perturbações do espectro do autismo}

São conhecidas as birras violentas, frequentes, prolongadas e muito difíceis de controlar que acompanham as perturbações do espectro do autismo, justificando o recurso à medicação. ${ }^{15,23,24}$ Devem-se a múltiplos factores: a falta de recurso à linguagem para manifestar vontades ou frustrações, a falta de reciprocidade nas trocas sociais, as dificuldades de comunicação, a insensibilidade à dor, a sensibilidade exagerada a estímulos auditivos e/ou visuais e o défice cognitivo frequentemente associado. ${ }^{15}$

\section{Perturbação de défice de atenção e hiperactividade} Na perturbação de défice de atenção e hiperactividade (PDAH), a desatenção, a hiperactividade e a impulsividade são consideradas factores predisponentes para a ocorrência de birras..$^{1,3,11,16}$ Isto deve-se ao facto destas crianças terem dificuldade em seguir instruções e em esperar pela sua vez, sendo por estes motivos excluídas das brincadeiras dos seus pares, o que lhes causa frustração. Também é causa de frustração o insucesso escolar motivado pelo défice de atenção. As birras e o comportamento disruptivo melhoram com a terapêutica farmacológica da PDAH, sendo o metilfenidato a droga de primeira linha, na dose de $0,5-2 \mathrm{mg} / \mathrm{kg} / \mathrm{dia}^{16}$

\section{Perturbações da visão}

As perturbações da visão são motivo de frustração e estas crianças podem ter birras excessivas. ${ }^{17}$ Podem ser uma das causas de birras na idade escolar e na escola, pelo que se recomenda uma avaliação da visão em qualquer criança que faça birras na escola.

\section{Perturbações da audição}

Da mesma forma, as perturbações da audição podem dar lugar a birras pela frustração que ocasionam. A surdez profunda tem uma prevalência de 1-2\%o e a mode- 
rada de 6 -10\%o. ${ }^{18}$ Também se acompanham de dificuldades linguísticas, que são outro factor desencadeante.

\section{Dificuldades escolares}

As dificuldades escolares podem motivar birras, tanto em casa como na escola. ${ }^{19}$ Podem ter origem numa perturbação da visão ou da audição que dificultem a aprendizagem. As dificuldades específicas da aprendizagem como a dislexia, a disgrafia, a disortografia ou a discalculia são motivo de grande frustração e causadoras de birras.

\section{Síndrome de Prader-Willi}

O síndrome de Prader-Willi (SPW) resulta da falta de expressão dos genes paternos no cromossoma 15 (região 15q11.2-q13) e tem uma prevalência de $1 / 15.000$ a $1 / 30.000 .{ }^{20}$ Caracteriza-se por hipotonia, dificuldades alimentares e atraso do crescimento e do desenvolvimento psicomotor nos primeiros 1-2 anos de vida. Após esse período, instala-se uma polifagia acentuada com ausência de saciedade, conduzindo a uma obesidade mórbida. Outras características do SPW são: o hipogonadismo, o hipogenitalismo (que se manifesta no rapaz por criptorquidia e micropénis), a baixa estatura, mãos e pés pequenos, pele clara, cabelo arruivado, boca pequena e palato alto. As birras, por vezes difíceis de controlar, fazem parte do quadro clínico do SPW, juntamente com o défice cognitivo, a perturbação da linguagem e outras perturbações comportamentais (como a teimosia, o comportamento manipulativo e controlador, o défice de atenção e o comportamento compulsivo).

\section{Síndrome do $X$ frágil}

O síndrome do $X$ frágil, é a segunda maior causa de défice cognitivo de origem genética (a primeira é a Trissomia 21), acompanhando-se de perturbação da linguagem, défice de atenção e hiperactividade, impulsividade, birras difíceis de controlar, com grande agressividade, podendo provocar lesões nos próprios e nos outros, justificando terapêutica farmacológica. ${ }^{21,22}$

\section{PREVENÇÃO}

Tanto as birras ditas normais como as ditas patológicas causam grande incómodo aos pais, sobretudo quando ocorrem em lugares públicos. ${ }^{4} \mathrm{~A}$ forma como lidam com elas nem sempre é a melhor, levando à sua intensifica- ção e prolongamento, pelo que devem ser aconselhados de modo a evitá-las ou controlá-las.

A melhor maneira de lidar com crianças que fazem birras é impedir que elas ocorram, percebendo quais os factores desencadeantes e evitando-os. ${ }^{1,2,4-9,11,12}$

Assim:

- devem ser respeitadas as necessidades de sono da criança, como, por exemplo, a necessidade de sesta;

- deve-se evitar que a criança sinta fome, respeitando o horário das refeições e, em caso de saída, tendo sempre à mão algum alimento;

- os objectos proibidos devem estar fora da sua vista;

- os brinquedos e jogos devem ser apropriados à sua idade, de modo a não causarem frustração;

- sempre que possível, deve ser dada à criança a oportunidade de fazer escolhas como, por exemplo, escolher a roupa ou os sapatos ou decidir se prefere comer um alimento ou outro;

- deve-se recorrer ao aviso prévio, dizendo, por exemplo, à criança que irá para a cama assim que terminar a leitura da história ou logo que termine um certo programa de televisão.

\section{INTERVENÇÃO}

Uma vez iniciada a birra, não vale a pena chamar a criança à razão. Também não se deve castigar a criança por fazer uma birra, nem se deve recompensar a birra, ou seja, fazer-lhe a vontade quando faz birra. Deve-se actuar logo no início da birra antes que a criança perca totalmente o controle, desviando a sua atenção, levando-a para outro local (ir para outra divisão da casa, sair do supermercado), contendo a criança em caso de ela bater ou se magoar, ignorando a birra nalguns casos ou usando o efeito de surpresa. ${ }^{1,2,4-9,11,12}$

Em caso de birras difíceis e com o objectivo de melhor planear a sua prevenção e controle, vários autores recomendam que os pais façam um diário das birras do seu filho, preenchendo uma grelha semanal, onde registam a descrição de cada birra, a sua duração, os factores desencadeantes, o local onde ocorreram, as estratégias utilizadas para controlar a birra e respectiva eficácia e o que aconteceu após a birra. ${ }^{1,5,6}$

\section{TERAPÊUTICA}

$\mathrm{Na}$ ausência de uma patologia de base, as estratégias de prevenção e de intervenção acima descritas são sufi- 
cientes para controlar as birras.

Havendo uma patologia de base, para além destas estratégias, a intervenção terapêutica deve ser dirigida a essa patologia.

A terapêutica farmacológica das birras só tem indicação quando estas surgem associadas a perturbações graves do neurodesenvolvimento, situações em que podem ser particularmente violentas e difíceis de controlar. É o que acontece nas perturbações do espectro do autismo, no síndrome do X frágil ou no défice cognitivo profundo. . $^{15,21-24}$

O fármaco habitualmente utilizado é a risperidona (0,5 mg uma ou duas vezes por dia), obtendo-se uma redução das birras, da agressividade e da auto-agressão.

\section{REFERÊNCIAS BIBLIOGRÁFICAS}

1. Needlman R. Temper tantrums. In: Parker S, Zuckerman B, Augustyn M, editors. Developmental and Behavioral Pediatrics: a handbook for primary care. Philadelphia, PA: Lippincott Williams and Wilkins; 2005. p. 338-41.

2. Potegal $M$, Davidson RJ. Temper tantrums in young children: 1 . Behavioral composition. J Develop Behav Pediatr 2003 Jun; 24 (3): 140-7.

3. Harrington RG. Temper tantrums: guidelines for parents. NASPresources, 2004. Disponível em. http://ww.nasponline.org [acedido em 03/1/2009]

4. Gavin ML. Temper tantrums. Nemours Foundation. KidsHealth for parents. Fev 2005. Disponível em: http://www.kidshealth.org [acedido em 03/1/2009].

5. Raising Children Network (Australia). Temper Tantrums. May 2006. Disponível em: http://www.raisingchildren.net.au [acedido em 03/11/2009].

6. Oesterreich L. Understanding Children:Temper Tantrums. Ames, IO: Iowa State University Cooperative Extension Service; 2003.

7. Gouveia R. A criança e a birra. Children's Practice 2009 Jan-Fev; 1: 27.

8. CS Mott Children's Hospital. University of Michigan Health System. Temper Tantrums. 2006. Disponível em: http://www.med.umich.edu [acedido em 03/1/2009].

9. Temper Tantrums and Childhood. Disponível em: http://www.medem. com [acedido em 03/11/2009].

10. Temper Tantrums. Ask Dr Sears, 2006. Disponível em: http://www. askdrsears.com [acedido em 03/1/2009].

11. Healthwise. Temper Tantrums: Topic Overview. WebMD Medical Reference from Healthwise. Dez 2006. Disponível em: http://www.children. webmd.com [acedido em 03/11/2009].

12. Hoecker JL. Temper Tantrums: how to keep the Peace. Mayo Foundation for
Medical Education and Research. Jun 2008. Disponível em: http://www.mayoclinic.com [acedido em 03/1/2009].

13. Kastner T, Walsh K. Mental Retardation: behavioral problems. In: Parker S, Zuckerman B, Augustyn M, editors. Developmental and Behavioral Pediatrics: a handbook for primary care. Philadelphia, PA: Lippincott Williams and Wilkins 2005. 52: 234-7.

14. Coplan J. Language Delays. In: Parker S, Zuckerman B, Augustyn M, editors. Developmental and Behavioral Pediatrics: a handbook for primary care. Philadelphia, PA: Lippincott Williams and Wilkins 2005. 49: 222-6.

15. Caronna E B. Autism. In: Parker S, Zuckerman B, Augustyn M, editors. Developmental and Behavioral Pediatrics: a handbook for primary care. Philadelphia, PA: Lippincott Williams and Wilkins 2005. p. 124-9.

16. Parker S. Attention deficit and hyperactivity disorder. In: Parker S, Zuckerman B, Augustyn M, editors. Developmental and Behavioral Pediatrics: a handbook for primary care. Philadelphia, PA: Lippincott Williams and Wilkins; 2005. p. 114-23.

17. Msall M. Visual impairment. In: Parker S, Zuckerman B, Augustyn M, editors. Developmental and Behavioral Pediatrics: a handbook for primary care. Philadelphia, PA: Lippincott Williams and Wilkins; 2005. p. 366-9.

18. Wills L M, Wills K E. Hearing impairment. In: Parker S, Zuckerman B, Augustyn $M$, editors. Developmental and Behavioral Pediatrics: a handbook for primary care. Philadelphia, PA: Lippincott Williams and Wilkins; 2005. p. 215-26.

19. Dworkin P. School failure. In: Parker S, Zuckerman B, Augustyn M, editors. Developmental and Behavioral Pediatrics: a handbook for primary care. Philadelphia, PA: Lippincott Williams and Wilkins; 2005. p. 280-4.

20. Cassidy SB, Driscoll DJ. Prader-Willi syndrome. Eur J Hum Genet 2008 Sep; $17(1): 3-13$

21. Hagerman R. Fragile X Syndrome. In: Parker S, Zuckerman B, Augustyn M, editors. Developmental and Behavioral Pediatrics: a handbook for Primary Care. Philadelphia, PA: Lippincott Williams and Wilkins; 2005. p. 195-8.

22. Jewell J A. Fragile X Syndrome. Mar 2009. Disponível em: http://www.emedicine.medscape.com [acedido em 03/11/2009].

23. Myers M. Management of children with autism spectrum disorders. Pediatrics 2007 Nov; 120 (5): 1162-82.

24. McCracken JT, McCough J, Shah B, Cronin P, Hong D, Aman MG, et al; Research Units in Pediatric Pharmacology Autism Network. Risperidone in children with autism and serious behavioral problems. N Engl J Med 2002 Aug 1; 347 (5): 314-21.

A autora declarou não possuir conflitos de interesses

ENDEREÇO PARA CORRESPONDÊNCIA

Rosa Gouveia

Rua Cidade de Cádiz, 25 - $3^{\circ}$ Esq

1500-156 Lisboa

E-mail: direccao@sec-desenvolvimento-spp.com

\section{ABSTRACT}

\section{TEMPER TANTRUMS IN CHILDREN}

The A. reviews causes, manifestations and prevalence of temper tantrums in children, considers temper tantrums in neurodevelopmental and genetic disorders and points out situations in which drug therapy is needed. The A. also recommends counselling concerning strategies to be used by parents in order to deal with their child's temper tantrums.

Keywords: Temper Tantrums; Child. 